\title{
A case of UV prolapse with cervical intraepithelial neoplasia 2
}

\section{Suvarna Jyothi Ganta*, Priyadarshini Holkar, Trishula Dabade, Surjeetkaur Sharma}

Department of Obstetrics and Gynecology, Chinmaya Mission Hospital, Bangalore, Karnataka, India

Received: 05 October 2016

Revised: 14 October 2016

Accepted: 03 November 2016

\section{*Correspondence:}

Dr. Suvarna Jyothi Ganta,

E-mail: suvarnajyothi0705@gmail.com

Copyright: (C) the author(s), publisher and licensee Medip Academy. This is an open-access article distributed under the terms of the Creative Commons Attribution Non-Commercial License, which permits unrestricted non-commercial use, distribution, and reproduction in any medium, provided the original work is properly cited.

\begin{abstract}
UV prolapse is a common condition seen in India, usually associated with multiparity and in the post-menopausal age group. Cervical cancer is also the most common genital tract malignancy encountered in the developing countries like India. The continual injury and mechanical irritation of the prolapsed cervix can lead to infection, bleeding, ulcers and occasionally malignancy. We present a case of a 44 year old woman who presented with prolapse and hypertrophied anterior lip of the cervix with a decubitus ulcer, which on biopsy was confirmed to be a CIN 2 lesion. Though prolapse and cancer of the cervix are common conditions seen in developing countries their co-existence is found rarely. Hence cytological evaluation with pap smear and if needed colposcopic guided cervical biopsy should be mandatorily carried out in the pre-operative work up.
\end{abstract}

Keywords: Cervical cancer, Hysterectomy, CIN, Prolapse, Prevalence, Pre-malignant-lesion

\section{INTRODUCTION}

Pelvic organ prolapse (POP) is a common condition affecting parous women in the reproductive and postmenopausal age group. Although varying degrees of pelvic organ prolapse are frequently observed, the condition seldom causes symptoms or is bothersome to the patient thus delaying their diagnosis and intervention.

In India it is an enormous disease burden on the women belonging to the lower socio-economic strata, it is found that among women visiting hospitals in Bengal, Delhi, Punjab and Uttar Pradesh with gynaecological problems, 1 in 5 are suffering from uterovaginal prolapse. Many studies have revealed that in India the prevalence rate is $15-20 \%$, in northern India it is $7.6 \%$, Eastern India $20 \%{ }^{1}$ In south India, Tamilnadu, the incidence of uterine prolapse is $0.7 \%$ and in Karnataka the incidence of uterine prolapse is $3.4 \%$. Internationally according to Oxford Family Planning Association, UK, the hospital admission for uterine prolapse is $20.4 \%$ and surgery for prolapse is $16.2 \%$.
Cervical cancer is the second most common cancer in India in women accounting for $22.86 \%$ of all cancer cases in women. The lesion usually starts at the transformation zone as intraepithelial neoplasm (CIN) and then progresses from carcinoma in situ to invasive carcinoma. Longstanding chronic inflammation of the prolapsed cervix with prolonged mechanical irritation, can lead to cervical malignancy. Earlier it was thought that the cornified cervical epithelium, minimal vaginal secretions (post-menopausal) and free drainage makes the prolapsed cervix resistant to the development of carcinoma. But there have been many studies in India and around the world showing the incidence of genital malignancy to be $0.3-0.8 \%$ in post hysterectomy specimen in unanticipated cases of prolapse. The carcinoma of the cervix and uterine prolapse are usual in developing conditions, but the combination of these two is an unusual occurrence. The case is reported because of its rarity. 


\section{CASE REPORT}

A 44 year old housewife of low socio-economic background presented to the OPD with complaints of mass per vagina since 3 years, gradually increasing in size. 15 days prior to the hospital visit, she developed lower abdominal pain, foul smelling bloody discharge and difficulty in voiding. She was P3L2 with first being a vaginal delivery at home, baby died after birth, second child delivered through LSCS and the third a VBAC. She had regular menstrual cycles and was sexually active. General physical examination was normal. Vitals were stable. On local examination, cervix was seen lying outside the vaginal introitus with foul smelling blood tinged discharge, a $3 \times 2 \mathrm{~cm}$ ulcer was seen on the anterior lip of the cervix. Per vaginal examination revealed third degree cervical descent with infra vaginal cervical elongation of $9 \mathrm{~cm}$, anterior lip of cervix was grossly and disproportionately hypertrophied and congested, os was seen posteriorly to the mass, with congested posterior lip.

No cystocele or rectocele was seen. On admission patient received intravenous antibiotics and vaginal packing with topical estrogen cream and metronidazole ointment to decrease the congestion and local infection. Pap smear showed cervical metaplasia .Patient underwent vaginal hysterectomy after 6 days, during surgery the bladder was densely adherent to the previous scar, the uterovesical fold was drawn high, the bladder was dissected with sharp dissection and the hysterectomy was carried out. Histopathology of specimen showed koilocytic atypia with dysplasia involving upper third to half of the epithelium suggesting CIN 2. Patient was followed up on the 8th post op day and 2 months post operation, is recovering well.

\section{DISCUSSION}

Pelvic floor defects may be caused as a result of childbirth, by the stretching and tearing of the endopelvic fascia, levator muscles and perineal body. Partial pudendal and perineal neuropathies, genital atrophy and hypoestrogenism (post menopause) also play important contributory roles in the pathogenesis of prolapse. ${ }^{2}$ Prolapse may potentially result from pelvic tumors, sacral nerve disorders and diabetic neuropathy, obesity, chronic pulmonary disease, smoking, constipation (increased intra-abdominal pressure). Typically women will complain of a bulge in the lower vagina or the cervix protruding through the vaginal introitus, other symptoms include sensation of vaginal fullness or pressure, sacral back pain on prolonged standing, vaginal spotting from ulceration of the protruding cervix or vagina, coital difficulty, lower abdominal discomfort, voiding and defecatory difficulties.

Surgical strategies for prolapse can be categorized broadly by reconstructive and obliterative techniques. ${ }^{3}$ In utero-vaginal prolapse, cervix is usually hypertrophied, thickened, keratinized, everted, with ectropion. It is common to find trophic ulcers, hyperpigmentation, and nabothian follicles on the cervix. Histopathology usually shows chronic cervicitis, keratinization and squamous metaplasia. Intraepithelial neoplasia is a rare finding. In literature the incidence of unanticipated malignant and premalignant lesions of the cervix among asymptomatic women undergoing hysterectomy for prolapse varies between 0.7 and $2.6 \%{ }^{4}$

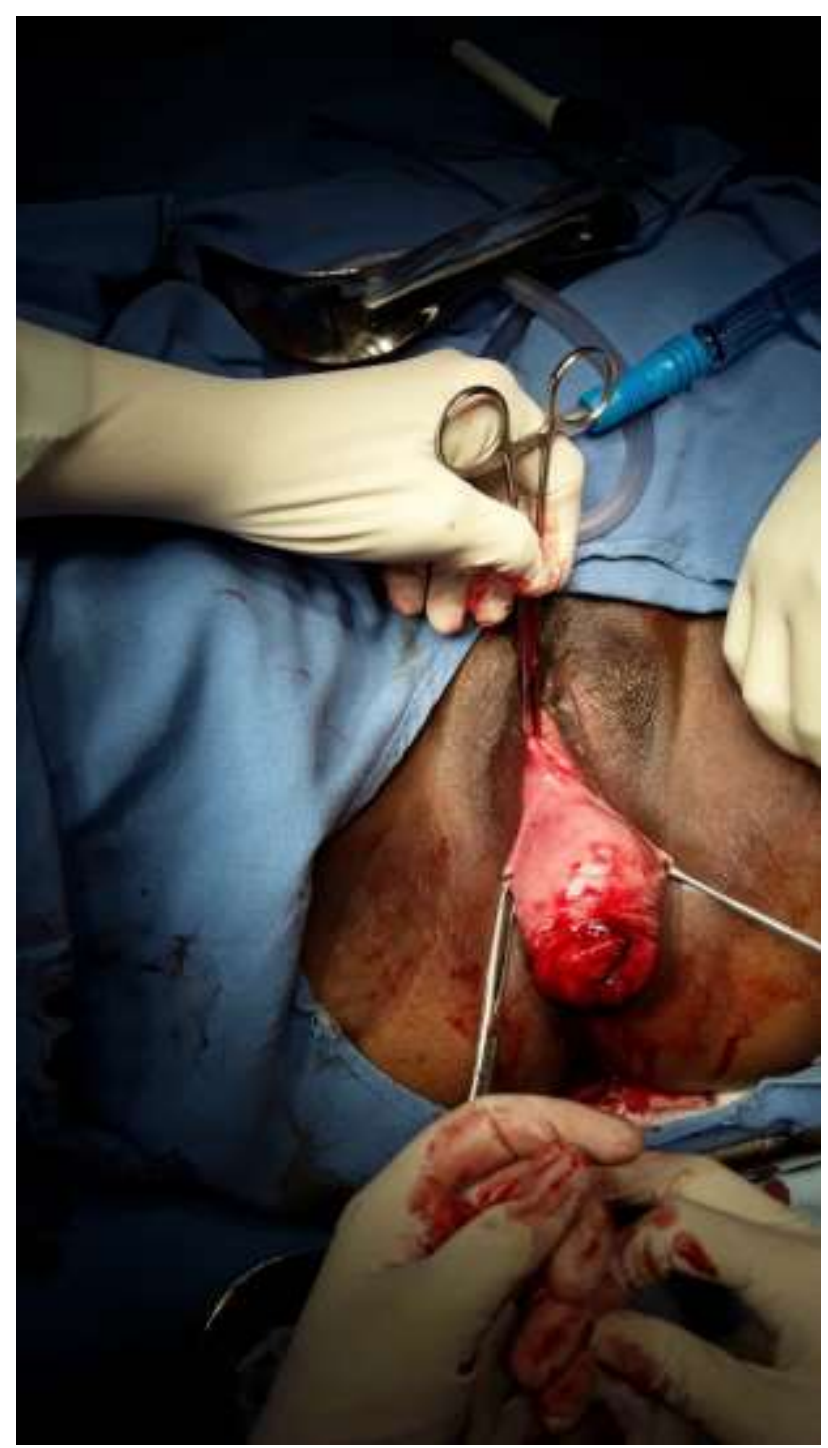

Figure 1: Hypertrophied anterior lip of cervix with decubitus ulcer.

Cervical cancer is the leading cancer among women in terms of incidence i.e. 2 in 12 according to the population Based Cancer Registries (PBCRs) in India and has the second highest incidence rate after breast cancer in the rest of the PBCRs. Increasing parity has been associated with development of cervical neoplasia, which can be due to the earlier sexual activity, progestin exposure effect, immunosuppression during pregnancy, hormonal influences on cervical epithelium and physical trauma in vaginal deliveries. ${ }^{1,4}$ 


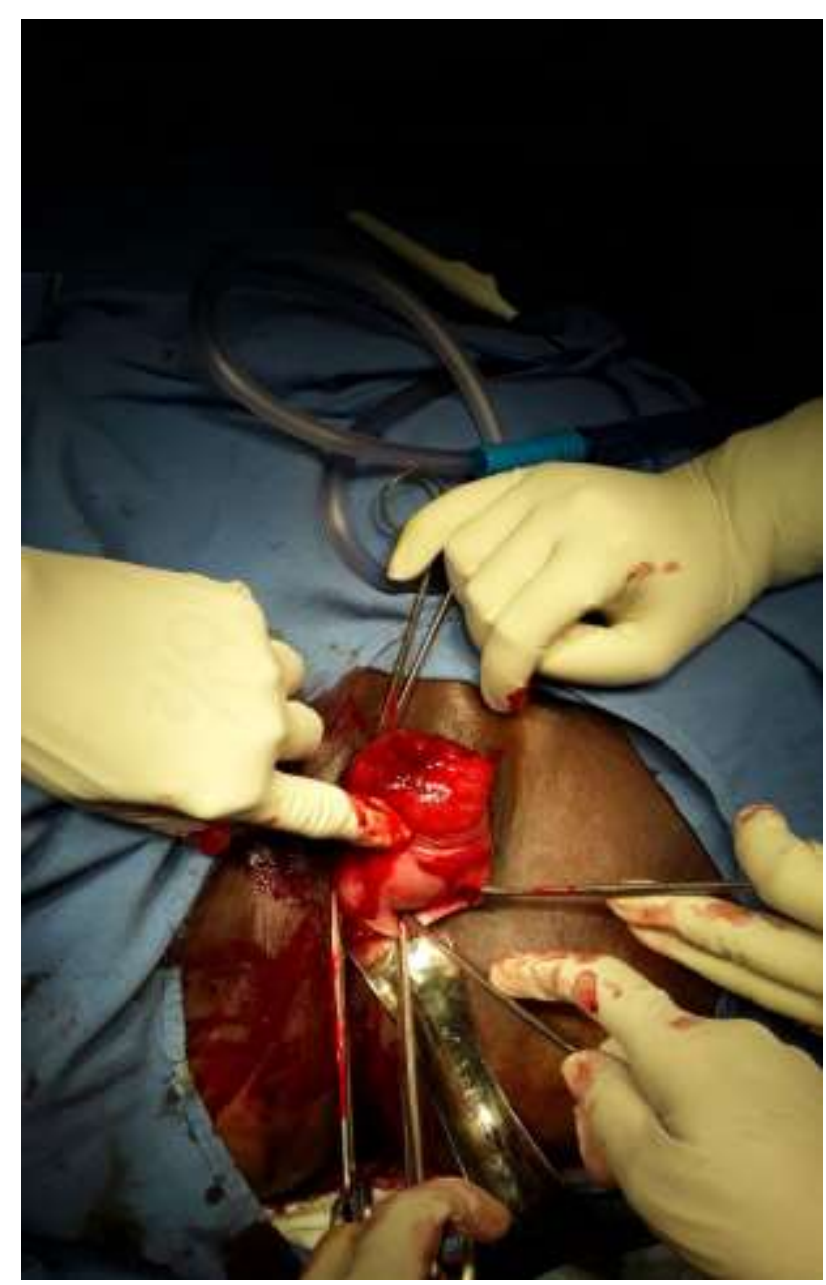

Figure 2: Cervical external OS seen posteriorly.

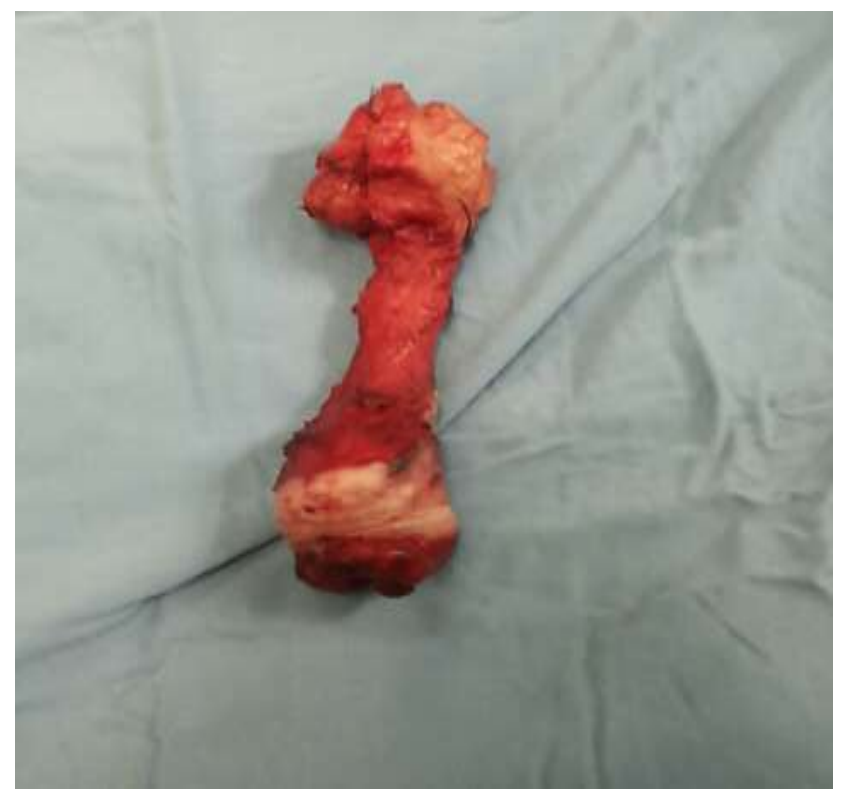

Figure 3: Post-operative specimen (anteriorly).

CIN (cervical intraepithelial neoplasia) starts at the transformation zone, especially in relation to the squamous metaplasia and reserve cell hyperplasia. About one quarter of the cases of CIN 1 and 2 will progress to a more severe lesion without treatment and over a half of the untreated cases of CIN 3 will eventually develop invasive carcinoma. ${ }^{5}$ A rare case of primary vaginal carcinoma (verrucous epidermoid) in a 73-year-old P11L11 female associated with vaginal prolapse which has occurred 16 years after transvaginal hysterectomy has been reported in literature. ${ }^{6}$

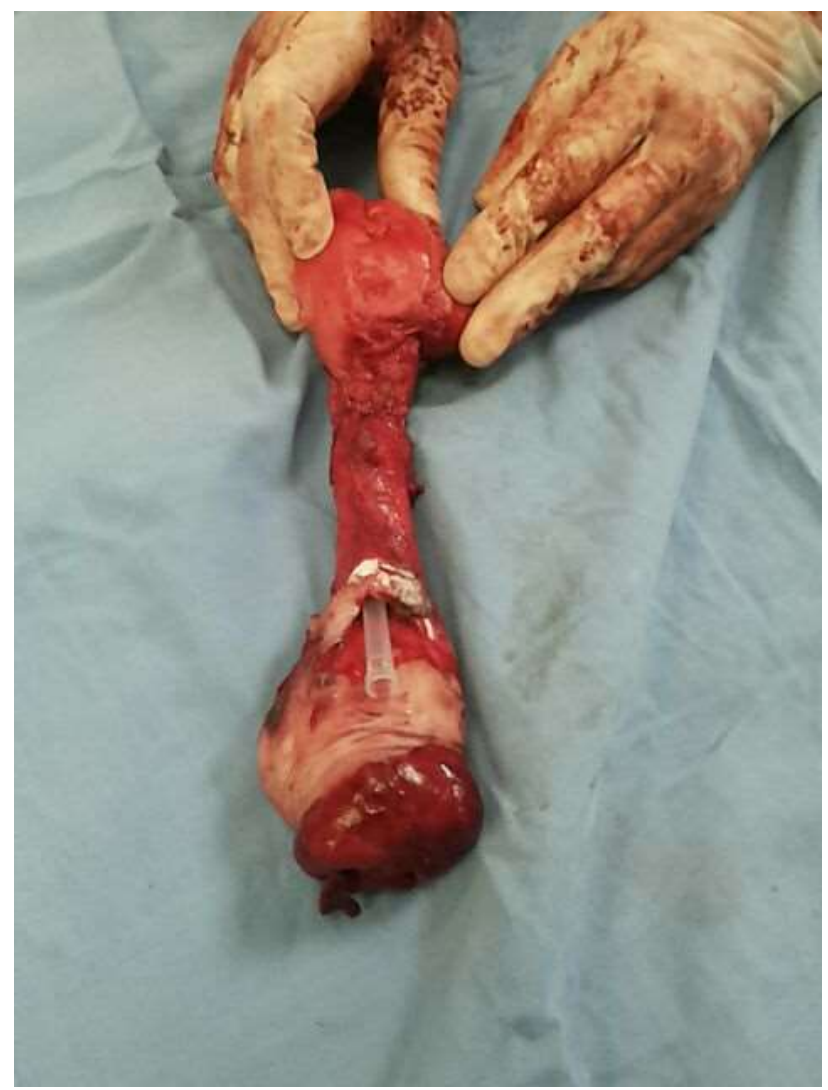

Figure 4: Post-operative specimen (posteriorly).

Vaginal hysterectomy is a frequently carried out operation for POP, the aim of surgery can be 1) restorative, 2)compensatory or 3)obliterative ${ }^{7}$.When conservative uterus-sparing procedure is elected, a thorough and complete preoperative assessment should be done to exclude presence of any precancerous or cancerous pathological conditions of the uterus. Carcinoma of the cervix and uterine prolapse are prevalent in developing nations, but the combination of these two is an unusual occurrence. Hysterectomy for CIN has often been considered an overzealous treatment, however if child bearing is not further desired and FIGO staging is strictly limited to $1 \mathrm{~A} 1$, then the best treatment is vaginal hysterectomy.

The other indications for TVH in prolapse with CIN lesions are:

1. Co-existent conditions like prolapse or fibroids. 
2. Persistent abnormal Pap smear following conservative management of cervical intraepithelial neoplasia (CIN).

3. In cases where a long term follow up after CIN is not possible.

4. The patient expresses a fear for conservative surgery.

Randomized controlled trials have demonstrated that women treated by vaginal hysterectomy experience lower morbidity, less pain, more rapid recovery and a more rapid return to normal activities compared with abdominal or laproscopically assisted $\mathrm{VH}^{8}$

Grigordiadis et al. reported the finding of CIN as $0.9 \%$ in post hysterectomy specimen. ${ }^{9}$ Wan OY et al. reported the risk of CIN as $0.78 \%$ in his study, the majority of women in the study by Duhan et al were in the fourth to sixth decade of life, multiparous, and with symptoms of prolapse. ${ }^{10,11}$ Although $88.28 \%$ of cervices revealed chronic cervicitis, 5 cases $(1.36 \%)$ had evidence of invasive cervical malignancy on histology. Cuzick et al. found one case $(0.3 \%)$ of cervical cancer in a 71 -year-old patient who had negative smear tests 14 months before surgery and one case $(0.3 \%)$ of CIN-3 in a 66-year-old patient with normal smear test results 3 years before surgery and 3 cases of CIN-1 with normal smear tests 6 months to 3 years before surgery. ${ }^{12}$

Padam RP, conducted a study among women with pelvic organ prolapse in rural parts of Nepal to determine the incidence of preinvasive and invasive carcinoma of the cervix, he found that the incidence of CIN 1 as $52 \%$, CIN 2 as $32 \%$, CIN 3 to be $9.6 \%$ and invasive carcinoma $1.5 \%$ in 601 women with abnormal cytology and histopathology findings, who underwent hysterectomy for prolapse. $^{13}$

Dayal study in north India also constituted CIN I (21.70\%) and CIN II (1.27\%). cervical intraepithelial neoplasia I $(21.70 \%)$, and others, but carcinoma cervix was not present. ${ }^{14}$ According to a study done in Pakistan by Mahboob R, occult squamous cell carcinoma in $1.02 \%$ of cases were reported. ${ }^{15}$ Bonner et al found in early 70 's, $26 \%$ of vaginal hysterectomy specimen had unsuspected pathological findings. ${ }^{16}$

Chronic cervicitis is a precursor for premalignant and malignant cervical lesions. Direct mechanical irritation, coupled with longstanding chronic inflammation of thirddegree prolapse, may predispose to the development of malignancy. Hence, common efforts must be taken for early diagnosis of cervical pathologies in uterine prolapse before the complications arise. Asymptomatic women with utero-vaginal prolapse may have associated premalignant lesions which may not be detected by conventional screening methods. This should be explained preoperatively for women undergoing surgery, especially if conservative management is considered. ${ }^{17}$ Hence, besides regular cervical screening, colposcopic examination and cervical biopsy, along with endocervical sampling, may be performed as a routine prior to surgery for longstanding prolapse.

Funding: No funding sources

Conflict of interest: None declared

Ethical approval: Not required

\section{REFERENCES}

1. Bijalwan RP, Bhagavatula M , Semwal VD, Rawat $\mathrm{P}$, Anand V. Morbidity of Uterine Prolapsed among the Women in the Chakrata Block of Dehradun District. Indian Journal of Community Health. 2015;27(1):103-9.

2. Goldberg RP. Effects of Pregnancy and Childbirth on the Pelvic Floor. Chapter 3, Urogynaecology in Primary Care, pp. 21-33, Springer. 2007.

3. Jelovsek JE, Maher C, Barber MD. Pelvic organ prolapse. Lancet. 2007;369(9566):1027-38.

4. Tailor HJ, Bhagat VM, Patel PR, Patel A, Italiya SL. Pap smear findings in uterine prolapse: a coincidence or indicator for impending malignancy. Int J Med Sci Public Health. 2016;5(4):819822.

5. Epithelial Abnormalities of the genital tract, chapter 25 , page 414, Jeffcott's principles of gynecology, seventh edition, Jaypee brother's medical publisher's ltd. 2008.

6. Kowalski J, Savage J, Bradley CS. Vaginal cancer in patient presenting with advanced pelvic organ prolapse: case report and literature review. Proceedings in Obstetrics and Gynecology. 2015;5(1):8.

7. Gleason JL, Richter HE. Berek and Novak's Gynecology page 922, chapter 27, pelvic organ prolapse, 15th edition, Lippincott, Williams and Wilkins. 2012.

8. Robert Kovac S. Vaginal hysterectomy, Chap 32B, page762, TeLinde's Operative Gynaecology,10th edition, Wolters Kluwer. 2009.

9. Grigordiadis T, Valla A, Zacharakis D, Protopapas A, Athanasiou S. Vaginal hysterectomy for uterovaginal prolapse: what is the incidence of concurrent gyneco-logical malignancy? Int Urogynecol J. 2015;26(3):421-5.

10. Wan OY, Cheung RY, Chan SS, Chung TK. Risk of malignancy in women who underwent hysterectomy for uterine prolapse. Aust N Z J Obstet Gynaecol. 2013;53:190-6.

11. Duhan N, Kadian YS. Uterovaginal Prolapse and Cervical Cancer: A Coincidence or an Association. Journal of Gynecologic Surgery. 2009;24(4):145-50.

12. Cuzick J, Clavel C, Petry KU, Meijer CJ, Hoyer H, Ratnam S, et al. Overview of the European and North American studies on HPV testing in primary cervical cancer screening. Int $\mathrm{J}$ Cancer. 2006;119(5):1095-101.

13. Raj PP. Preinvasive and invasive neoplasm of the cervix among the women with uterine prolapse, Medica Innovatica. Academic Journal. 2013;2(2):36. 
14. Dayal S, Nagrath A. Audit on preinvasive and invasive neoplasm of the cervix and associated pathologies among the women with uterine prolapse in rural women of North India. Clinical Cancer Investigation Journal. 2016;5(2):110.

15. Mehboob R, Ahmad N. Unexpected pathology at vaginal hysterectomy for genital prolapse, Department of Obstetrics and Gynecology, Nishtar Hospital, Multan. Pak J Med Res. 2002;41(4):142-4.

16. Bonnar J, Kraszewski A, Davis WB. Incidental pathology at vaginal hysterectomy for genital prolapse. BJOG: An International Journal of Obstetrics and Gynecology. 1970;77(12):1137-9.

17. Elbiaa AAM, Abdelazim IA. Unexpected premalignant gynecological lesions in women undergoing vaginal hysterectomy for utero-vaginal prolapse. Prz Menopauzalny. 2015;14(3):188-91.

Cite this article as: Ganta SJ, Holkar P, Dabade T, Sharma S. A case of UV prolapses with cervical intraepithelial neoplasia 2. Int J Reprod Contracept Obstet Gynecol 2016;5:4509-13. 